Sharif University of Technology
Scientia Iranica
Transactions E: Industrial Engineering
SCIENTIA

\title{
Determination of product acceptance for two suppliers with linear profiles
}

\author{
M. Aslam ${ }^{\mathrm{a}, *}$, M. Azam ${ }^{\mathrm{b}}$, and C.H. Jun ${ }^{\mathrm{c}}$ \\ a. Department of Statistics, Faculty of Science, King Abdulaziz University, Jeddah 21551, Saudi Arabia. \\ b. Department of Statistics and Computer Sciences, University of Veterinary and Animal Sciences, Lahore 54000, Pakistan. \\ c. Department of Industrial and Management Engineering, POSTECH, Pohang 37673, Republic of Korea.
}

Received 30 September 2018; received in revised form 1 May 2019; accepted 18 January 2020
KEYWORDS
Sampling plan;
EWMA statistic;
Linear profile;
Process-yield index;
Difference statistic.

\begin{abstract}
In the supplier management, it is necessary to compare the performances of two suppliers using linear profiles. In this study, the determination procedure for product acceptance was designed using the Exponentially Weighted Moving Average (EWMA) statistic based on the process-yield index applied to the linear profiles of two suppliers. The design parameters of the proposed plan were also determined to satisfy both the producer's and consumer's risks. The efficiency of the proposed sampling plan was compared to that of the sampling plan developed based on Wang's test statistic in terms of the sample size required for selecting a better supplier. To this end, a real example was presented to explain the proposed sampling plan.

(C) 2021 Sharif University of Technology. All rights reserved.
\end{abstract}

\section{Introduction}

Quality is a critical factor in selection of supplier, evaluation of manufacturing firms, reduction of rework and operation costs, and promotion of the share of companies in the market $[1,2]$. The process yield which is based on the Process Capability Index (PCI) is employed to judge the process performance of a supplier [3]. A yield index is used as one of the available tools for judging the quality or performance of two or more suppliers. A higher index results in higher quality and a smaller fraction of nonconforming product. According to Wang [4], "if the index value of one supplier can be shown to be significantly greater than that of another supplier, then the supplier with higher index value will incur lower costs". In [5-9], some studies were introduced that evaluated and determined

\footnotetext{
*. Corresponding author.

E-mail addresses: aslam_ravian@hotmail.com (M. Aslam); mazam72@yahoo.com (M.Azam); chjun@postech.ac.kr (C.H. Jun)
}

doi: $10.24200 /$ sci. 2020.51876 .2408 a better supplier including different PCIs under normal distribution. Lin and Pearn [10] compared multiple suppliers using PCI. Lin and Kuo [11] presented a method for multiple comparisons based on PCI.

A functional relationship between the dependent and explanatory variables is called a profile. Profile monitoring has drawn considerable attention in recent years owing to its wide applications in quality engineering. A review of the linear and nonlinear profiles was provided in [12]. More details about this type of studies can be seen in [13-20].

An acceptance sampling plan is one of the tools for inspecting products at the final stage [21]. The sampling plan is also used to select a better supplier to provide a good-quality product. Assume that according to the null hypothesis, the product from Suppler 1 is better than that from Supplier 2. A random sample with a particular size is selected from the submitted lot of each supplier, and the decision on the hypothesis can be made based on a suitable statistic. Wang [4] developed a difference test statistic for two suppliers using linear profile under a normal distribution. In this study, a sampling plan was designed based on 
this test statistic; however, this test statistic should be further improved by the Exponentially Weighted Moving Average (EWMA) statistic.

Usually, a sampling plan provides the decision about the submitted product using the current state only. Application of EWMA statistic in a sampling plan can increase the accuracy of the decision on the acceptance of many products. The EWMA statistic enables the engineer to use the current and past information to make the final decision on supplier selection. According to Montgomery [3], this statistic weights the sample in an exponentially decreasing order. Aslam et al. [22] designed a sampling plan using EWMA statistic when the quality of interest followed the normal distribution. More details on the applications of the sampling plans can be seen in [23-32]. Moreover, some of the sampling plans have been developed based on EWMA statistic (see for example [33-43].

The present study aimed to improve the test statistic proposed by Wang [4] using an EWMA scheme in the presence of the available profile data on two suppliers. A sampling plan is also designed using the proposed EWMA statistic. The efficiency of the proposed sampling plan is compared with that based on Wang's test statistic in terms of the sample size required for the selection of a better supplier among the two. The application of the proposed sampling plan is illustrated through an industrial example.

\section{Design of proposed EWMA plan}

Let $x_{i}$ denote the $i$ th level of the independent variable of interest and $y_{i j}$ the $j$ th sample of the response variable at the fixed level $x_{i}$. It is assumed that the following linear relationship of $x_{i}$ and $y_{i j}$ holds:

$$
\begin{aligned}
& y_{i j}=\beta_{0}+\beta_{1} x_{i}+\varepsilon_{i j}, \\
& i=1,2, \cdots, n ; \quad j=1,2, \cdots, k
\end{aligned}
$$

where $n$ is the number of levels of the independent variable, $k$ is the number of observations (or sample size), and $\beta_{0}$ and $\beta_{1}$ are the coefficients of the linear profile. Here, $\varepsilon_{i j}$ is the error term that follows a normal distribution with the mean of 0 and variance of $\sigma^{2}$. Note that $\left(y_{1 j}, y_{2 j}, \cdots, y_{n j}\right)$ is called the $j$-th profile.

Wang [4] proposed the following process-yield index for the response variable at level $x_{i}$ :

$$
\begin{aligned}
S_{p k_{i}} & =\frac{1}{3} \Phi^{-1}\left[\frac{1}{2} \Phi\left(\frac{U S L_{i}-\mu_{i}}{\sigma_{i}}\right)+\frac{1}{2} \Phi\left(\frac{\mu_{i}-L S L_{i}}{\sigma_{i}}\right)\right] \\
& =\frac{1}{3} \Phi^{-1}\left[\frac{1}{2} \Phi\left(\frac{1-c_{d r_{i}}}{c_{d p_{i}}}\right)+\frac{1}{2} \Phi\left(\frac{1+c_{d r_{i}}}{c_{d p_{i}}}\right)\right],
\end{aligned}
$$

where $U S L_{i}$ and $L S L_{i}$ are the upper and lower specification limits of the response variable at $x_{i}, \mu_{i}$ and $\sigma_{i}$ are the mean and standard deviation, respectively, of the response variable at $x_{i}, c_{d r_{i}}=\left(\mu_{i}-m_{i}\right) / d_{i}, c_{d r i}=$ $\sigma_{i} / d_{i}, m_{i}=\left(U S L_{i}+L S L_{i}\right) / 2$, and $d_{i}=\left(U S L_{i}-\right.$ $\left.L S L_{i}\right) / 2$. Here, $\Phi(x)$ is the cumulative distribution function of a standard normal distribution.

Wang [4] considered the following estimator of the process-yield index for a simple linear profile model in Eq. (1) as:

$$
S_{p k_{i}}=\frac{1}{3} \Phi^{-1}\left[\frac{1}{2} \Phi\left(\frac{1-\hat{c}_{d r_{i}}}{\hat{c}_{d p_{i}}}\right)+\frac{1}{2} \Phi\left(\frac{1+\hat{c}_{d r_{i}}}{\hat{c}_{d p_{i}}}\right)\right],
$$

where $\hat{c}_{d r_{i}}=\left(\hat{\mu}_{i}-m_{i}\right) / d_{i}$ and $\hat{c}_{d r_{i}}=\hat{\sigma}_{i} / d_{i}$.

Assume that there are two suppliers: Supplier 1 and Supplier 2. The problem here is whether to accept a lot from Supplier 1 or 2 who can provide a better quality. Suppose that Supplier 2 claims that their products are of better quality with a higher process-yield index than those provided by Supplier 1 . Based on their claim, we set the null and alternative hypotheses as follows:

$$
\left\{\begin{array}{l}
H_{0}: S_{p k A_{2}}-S_{p k A_{1}} \geq 0 \\
H_{1}: S_{p k A_{2}}-S_{p k A_{1}}<0
\end{array}\right.
$$

In case the sample information supports $H_{0}$, it can be concluded that Supplier 2 outperforms Supplier 1; therefore, a lot of products supplied by Supplier 2 should be accepted. Otherwise, a lot of products provided by Supplier 1 should be accepted. It is assumed that $k_{1}$ profiles are available at $n_{1}$ levels of the independent variable for Supplier 1 , and $k_{2}$ profiles are available at $n_{2}$ levels of the independent variable for Supplier 2.

Wang [4] derived the approximate normal distribution of the difference statistic $\hat{D}$ between Supplier 1 and Supplier 2 as:

$$
\hat{D}=\hat{S}_{p k A_{2}}-\hat{S}_{p k A_{1}} \sim N\left(S_{p k A_{2}}-S_{p k A_{1}}, \sigma_{s_{2}}^{2}+\sigma_{s_{1}}^{2}\right),
$$

where:

$$
\begin{aligned}
\sigma_{s_{1}}^{2} & =\frac{G_{1}^{2}\left[\phi\left(3 G_{1}^{2}\right)\right]^{2}}{2 n_{1}^{2} k_{1}\left[\phi\left(3 S_{p k A_{1}}\right)\right]^{2}}, \\
G_{1} & =\frac{1}{3} \Phi^{-1}\left\{\frac{n_{1}\left[2 \Phi\left(3 S_{p k A_{1}}\right)-1\right]-\left(n_{1}-2\right)}{2}\right\}, \\
\sigma_{s_{2}}^{2} & =\frac{G_{2}^{2}\left[\phi\left(3 G_{2}^{2}\right)\right]^{2}}{2 n_{2}^{2} k_{2}\left[\phi\left(3 S_{p k A_{2}}\right)\right]^{2}}, \\
G_{2} & =\frac{1}{3} \Phi^{-1}\left\{\frac{n_{2}\left[2 \Phi\left(3 S_{p k A_{2}}\right)-1\right]-\left(n_{2}-2\right)}{2}\right\} .
\end{aligned}
$$

In this study, the sampling plan was proposed using the EWMA scheme of the above difference test statistic. The proposed plan is given as follows: 
Step 1: At time $t$, obtain $k_{1}$ random profiles at $n_{1}$ levels of the independent variable for Supplier 1 and $k_{2}$ random profiles at $n_{2}$ levels of the independent variable for Supplier 2.

Step 2: Calculate the difference statistic $\hat{D}_{t}=$ $\hat{S}_{p k A_{2}}-\hat{S}_{p k A_{1}}$. Then, compute the following EWMA statistic:

$$
\hat{D}_{t}^{E W M A}=\lambda \hat{D}_{t}+(1-\lambda) \hat{D}_{t-1}^{E W M A},
$$

where $\lambda$ is a smoothing constant ranging from 0 to 1 . At $t=1$, we set $\hat{D}_{t}^{E W M A}=\hat{D}_{1}$.

Step 3: Accept the lot by Supplier 1 if $\hat{D}_{t}^{E W M A} \geq c$, or accept the lot by Supplier 2 instead, where $c$ is the acceptance constant to be determined.

The proposed sampling plan is based on the number of profiles (sample size) for each supplier $\left(k_{1}\right.$ and $k_{2}$ ) and the acceptance constant $c$ when the number of levels is specified. The acceptance constant $c$ should be determined to minimize the sample size while satisfying the producer's and the consumer's risks.

The smoothing constant $\lambda$ determines the rate at which the "previous lots" enter into the calculation of the EWMA statistic. A value of $\lambda=1$ implies that only the most recent measurement can affect the statistic. Hence, a large value of $\lambda$ gives more weight to the recent data and less weight to the older data. Further, a small value of $\lambda$ gives more weight to older data. The value of $\lambda$ ranging between 0.1 and 0.3 is recommended in practice [3].

First, the EWMA statistic for sufficiently large $t$ follows the normal distribution given as:

$$
\hat{D}_{t}^{E W M A} \sim N\left(S_{p k A_{2}}-S_{p k A_{1}},(\lambda / 2-\lambda)\left(\sigma_{s_{2}}^{2}+\sigma_{s_{1}}^{2}\right)\right) .
$$

Therefore, the Operating Characteristic (OC) function of the proposed plan is derived as shown in Box I, where $Z$ is the standard normal random variable. Finally, the lot acceptance probability is given as shown in Box II.

Assume that $\alpha$ is the producer's risk and $\beta$ the consumer's risk. The producer is interested in guaranteeing that the lot acceptance probability for a good lot should be greater than his confidence level, $1-\alpha$, at Acceptable Quality Level (AQL). The consumer requires that the lot acceptance for a bad lot be smaller than his/her risk at the Lot Tolerance Percent Defective (LTPD). Let $C_{A Q L_{1}}$ be the AQL value for Supplier 1 and $C_{A Q L_{2}}$ the AQL value for Supplier 2, $C_{L T P D_{1}}$ the LTPD value for Supplier 1, and $C_{L T P D_{2}}$ the LTPD value for Supplier 2. For simplicity, it is assumed that $n_{1}=n_{2}=n$ and $k_{1}=k_{2}=k$. The plan parameters of the proposed plan based on EWMA statistic are determined by solving the non-linear optimization problem in Eq. (7) as shown in Box III.

Here, we consider the cases where the quality level for Supplier 2 is higher than that for Supplier 1, i.e., $\Delta C_{A Q L}=C_{A Q L_{2}}-C_{A Q L_{1}}>0$ and $\Delta C_{L T P D}=$ $C_{L T P D_{2}}-C_{L T P D_{1}}>0$. There are many combinations of $\left(C_{A Q L_{2}}, C_{L T P D_{2}}, C_{A Q L_{1}}, C_{L T P D_{1}}\right)$ such as $(1.5,1.3$, $1.0,0.9)$ and $(1.6,1.4,1.1,1.0)$. It should be noted that $C_{A Q L}>C_{L T P D}$.

Tables 1 and 2 present the plan parameters of the proposed sampling plan for different values of smoothing constant and numbers of independent variable levels when $\Delta C_{A Q L}=0.5$ and $\Delta C_{L T P D}=0.4$. Two combinations of $\left(C_{A Q L_{2}}=1.5, C_{L T P D_{2}}=1.3\right.$, $\left.C_{A Q L_{1}}=1.0, C_{L T P D_{1}}=0.9\right)$ and $\left(C_{A Q L_{2}}=1.6\right.$, $\left.C_{L T P D_{2}}=1.4, C_{A Q L_{1}}=1.1, C_{L T P D_{1}}=1.0\right)$ are considered in this study. The producer's and the

$$
P\left(\hat{D}_{t}^{E W M A} \geq c\right)=P\left(Z \geq \frac{c-\left(S_{p k A_{2}}-S_{p k A_{1}}\right)}{\sqrt{(\lambda /(2-\lambda))\left[\frac{G_{1}^{2}\left[\phi\left(3 G_{1}^{2}\right)\right]^{2}}{2 n_{1}^{2} k_{1}\left[\phi\left(3 S_{p k A_{1}}\right)\right]^{2}}+\frac{G_{2}^{2}\left[\phi\left(3 G_{2}^{2}\right)\right]^{2}}{2 n_{2}^{2} k_{2}\left[\phi\left(3 S_{p k A_{2}}\right)\right]^{2}}\right]}}\right)
$$

Box I

$$
P\left(\hat{D}_{t}^{E W M A} \geq c\right)=1-\Phi\left(\frac{c-\left(S_{p k A_{2}}-S_{p k A_{1}}\right)}{\sqrt{(\lambda /(2-\lambda))\left[\frac{G_{1}^{2}\left[\phi\left(3 G_{1}^{2}\right)\right]^{2}}{2 n_{1}^{2} k_{1}\left[\phi\left(3 S_{p k A_{1}}\right)\right]^{2}}+\frac{G_{2}^{2}\left[\phi\left(3 G_{2}^{2}\right)\right]^{2}}{2 n_{2}^{2} k_{2}\left[\phi\left(3 S_{p k A_{2}}\right)\right]^{2}}\right]}}\right) .
$$


Minimize $k$

subject to :

$1-\Phi\left(\frac{c-\left(C_{A Q L_{2}}-C_{A Q L_{1}}\right)}{\sqrt{(\lambda /(2-\lambda))\left[\frac{G_{1}^{2}\left[\phi\left(3 G_{1}^{2}\right)\right]^{2}}{2 n^{2} k\left[\phi\left(3 C_{A Q L_{1}}\right)\right]^{2}}+\frac{G_{2}^{2}\left[\phi\left(3 G_{2}^{2}\right)\right]^{2}}{2 n^{2} k\left[\phi\left(3 C_{A Q L_{2}}\right)\right]^{2}}\right]}}\right) \geq 1-\alpha$,

$1-\Phi\left(\frac{c-\left(C_{L T P D_{2}}-C_{L T P D_{1}}\right)}{\sqrt{(\lambda /(2-\lambda))\left[\frac{G_{1}^{2}\left[\phi\left(3 G_{1}^{2}\right)\right]^{2}}{2 n^{2} k\left[\phi\left(3 C_{L T P D_{1}}\right)\right]^{2}}+\frac{G_{2}^{2}\left[\phi\left(3 G_{2}^{2}\right)\right]^{2}}{2 n^{2} k\left[\phi\left(3 C_{L T P D_{2}}\right)\right]^{2}}\right]}}\right) \leq \beta$.

\section{Box III}

consumer's risks are chosen by $\alpha=0.05$ and $\beta=0.10$ for all tables.

According to Tables 1 and 2, for all other same values, as n changes from 2 to 30 , there is a decreasing trend in $k$. As expected, smaller sample size (or profile) is required as a larger number of variables are used. It is also observed that the sample size becomes smaller when using smaller smoothing constant.

Tables 3 and 4 are reported when $\Delta C_{A Q L}=0.6$ and $\triangle C_{L T P D}=0.5$. Here, again, two combinations of ( $C_{A Q L_{2}}=1.6, C_{L T P D_{2}}=1.4, C_{A Q L_{1}}=1.0, C_{L T P D_{1}}=$ 0.9 ) and $\left(C_{A Q L_{2}}=1.7, C_{L T P D_{2}}=1.5, C_{A Q L_{1}}=1.1\right.$, $\left.C_{L T P D_{1}}=1.0\right)$ are considered.

As observed, the values of $k$ increased for these cases as compared with the ones in Tables 1 and 2 .

\section{Comparative study}

A sampling plan is designed for the comparison purpose using Wang's difference statistic given in Eq. (4). In fact, the plan based on Wang's test statistic is a special case of the proposed sampling plan with $\lambda=$ 1. In this section, the proposed sampling plan is compared with the plan developed based on Wang's testing procedure in terms of the required sample size. To compare the efficiency of both sampling plans, the same values of all specified parameters were selected. The plan parameters of the sampling plan proposed by Wang [4] are placed in the last columns of Table 2 (when $\Delta C_{A Q L}=0.5$ and $\Delta C_{L T P D}=0.4$ ) and Table 4 (when $\Delta C_{A Q L}=0.6$ and $\Delta C_{L T P D}=0.5$ ).

A comparison between these plans and those with $\lambda$ value smaller than 1 showed that the proposed EWMA plan could provide smaller values for $k$ than those of Wang's sampling plan. For example, when $C_{A Q L_{2}}=1.5, C_{L T P D_{2}}=1.3, C_{A Q L_{1}}=1.0, C_{L T P D_{1}}=$ 0.9 , and $n=5$, the value of $k$ for the proposed plan with $\lambda=0.1$ is 32 , while it is 589 for the sampling plan based on Wang's test statistic. Therefore, the proposed EWMA sampling plan looks more efficient than the sampling plan without the EWMA scheme. Practically, the values of $\lambda$ lying between 0.1 and 0.5 are preferable in industries. Therefore, the proposed plan is more efficient in this range.

\section{Application of the proposed plan}

In this section, the application of the proposed sampling plan in the leather industry [44] is discussed. Wang [4] used the leather industry data to discuss the application of his difference statistic. According to Wang [4], "the quality performance of leather dyeing process is characterized by a relationship between the leather color effluent and temperature. The corresponding color effluent was examined in $150 \mathrm{ml}$ water at five different temperatures including $25,32,39,46$, and $53^{\circ} \mathrm{C} "$.

Assume that the industry employs the proposed sampling plan with $\lambda=0.29$ and $n=5$ by specifying the values of $\Delta C_{A Q L}=0.5$ and $\Delta C_{L T P D}=0.4$. Then, according to Table $1, k=100$ and $c=0.4300$. Therefore, it is necessary to collect data for 100 profiles from two suppliers. Table 5 presents the specification limits as well as means and standard deviations (from both Suppliers 1 and 2) at five levels of the independent variable.

Based on the data listed in Table 5, the EWMA statistic based on Eq. (5) can be obtained 
Table 1. The plan parameters for the proposed plan when $\Delta C_{A Q L}=0.5$ and $\Delta C_{L T P D}=0.4$.

\begin{tabular}{|c|c|c|c|c|c|c|c|c|}
\hline \multirow{2}{*}{$n$} & \multicolumn{2}{|c|}{$\lambda=0.10$} & \multicolumn{2}{|c|}{$\lambda=0.15$} & \multicolumn{2}{|c|}{$\lambda=0.20$} & \multicolumn{2}{|c|}{$\lambda=0.29$} \\
\hline & $\boldsymbol{k}$ & $c$ & $k$ & $c$ & $\boldsymbol{k}$ & $c$ & $k$ & $c$ \\
\hline \multicolumn{9}{|c|}{$\left(C_{A Q L_{2}}=1.5, C_{L T P D_{2}}=1.3, C_{A Q L_{1}}=1.0, C_{L T P D_{1}}=0.9\right)$} \\
\hline 2 & 34 & 0.4243 & 53 & 0.4246 & 73 & 0.4249 & 109 & 0.4228 \\
\hline 4 & 32 & 0.4288 & 50 & 0.4287 & 70 & 0.4298 & 105 & 0.4286 \\
\hline 5 & 32 & 0.4306 & 48 & 0.4299 & 66 & 0.4298 & 100 & 0.4300 \\
\hline 10 & 26 & 0.4306 & 40 & 0.4306 & 57 & 0.4316 & 85 & 0.4311 \\
\hline 15 & 24 & 0.4299 & 34 & 0.4291 & 48 & 0.43 & 71 & 0.4293 \\
\hline 20 & 20 & 0.4277 & 30 & 0.427 & 41 & 0.4278 & 61 & 0.4273 \\
\hline 25 & 18 & 0.4254 & 27 & 0.4262 & 36 & 0.4255 & 55 & 0.4253 \\
\hline 30 & 17 & 0.425 & 24 & 0.4244 & 34 & 0.4255 & 49 & 0.4241 \\
\hline \multicolumn{9}{|c|}{$\left(C_{A Q L_{2}}=1.6, C_{L T P D_{2}}=1.4, C_{A Q L_{1}}=1.1, C_{L T P D_{1}}=1.0\right)$} \\
\hline 2 & 30 & 0.4105 & 46 & 0.4105 & 62 & 0.4107 & 96 & 0.4108 \\
\hline 4 & 30 & 0.419 & 47 & 0.4187 & 62 & 0.4174 & 95 & 0.4183 \\
\hline 5 & 30 & 0.4211 & 47 & 0.4192 & 64 & 0.4214 & 95 & 0.4197 \\
\hline 10 & 29 & 0.4254 & 44 & 0.4253 & 61 & 0.4253 & 93 & 0.4254 \\
\hline 15 & 27 & 0.4278 & 42 & 0.428 & 56 & 0.4272 & 86 & 0.4271 \\
\hline 20 & 26 & 0.4271 & 39 & 0.4279 & 54 & 0.4277 & 84 & 0.4281 \\
\hline 25 & 25 & 0.4292 & 37 & 0.4279 & 50 & 0.4281 & 77 & 0.4282 \\
\hline 30 & 23 & 0.4272 & 35 & 0.4282 & 47 & 0.4274 & 72 & 0.4276 \\
\hline
\end{tabular}

Table 2. The plan parameters for the proposed plan when $\Delta C_{A Q L}=0.5$ and $\Delta C_{L T P D}=0.4$.

\begin{tabular}{|c|c|c|c|c|c|c|}
\hline \multirow[b]{2}{*}{$n$} & \multicolumn{2}{|c|}{$\lambda=0.50$} & \multicolumn{2}{|c|}{$\lambda=0.75$} & \multicolumn{2}{|c|}{$\begin{array}{c}\text { Wang's test } \\
\text { statistic }\end{array}$} \\
\hline & $k$ & $c$ & $k$ & $c$ & $k$ & $c$ \\
\hline \multicolumn{7}{|c|}{$\left(C_{A Q L_{2}}=1.5, C_{L T P D_{2}}=1.3, C_{A Q L_{1}}=1.0, C_{L T P D_{1}}=0.9\right)$} \\
\hline 2 & 212 & 0.4229 & 381 & 0.4231 & 630 & 0.4233 \\
\hline 4 & 204 & 0.4289 & 365 & 0.4288 & 609 & 0.4289 \\
\hline 5 & 198 & 0.4300 & 356 & 0.4302 & 589 & 0.4298 \\
\hline 10 & 166 & 0.4305 & 298 & 0.4310 & 491 & 0.4306 \\
\hline 15 & 139 & 0.4294 & 252 & 0.4296 & 417 & 0.4292 \\
\hline 20 & 121 & 0.4273 & 216 & 0.4274 & 368 & 0.4276 \\
\hline 25 & 109 & 0.4262 & 195 & 0.4263 & 322 & 0.4254 \\
\hline 30 & 100 & 0.4243 & 173 & 0.4237 & 289 & 0.4239 \\
\hline \multicolumn{7}{|c|}{$\left(C_{A Q L_{2}}=1.6, C_{L T P D_{2}}=1.4, C_{A Q L_{1}}=1.1, C_{L T P D_{1}}=1.0\right)$} \\
\hline 2 & 186 & 0.4106 & 333 & 0.4110 & 551 & 0.4108 \\
\hline 4 & 191 & 0.4178 & 331 & 0.4176 & 562 & 0.4175 \\
\hline 5 & 184 & 0.4199 & 338 & 0.4199 & 553 & 0.4196 \\
\hline 10 & 179 & 0.4255 & 327 & 0.4255 & 543 & 0.4255 \\
\hline 15 & 170 & 0.4275 & 305 & 0.4274 & 504 & 0.4272 \\
\hline 20 & 159 & 0.4280 & 291 & 0.4276 & 480 & 0.4278 \\
\hline 25 & 149 & 0.4278 & 268 & 0.4279 & 446 & 0.4278 \\
\hline 30 & 141 & 0.4276 & 251 & 0.4274 & 426 & 0.4276 \\
\hline
\end{tabular}


Table 3. The plan parameters for the proposed plan when $\Delta C_{A Q L}=0.6$ and $\Delta C_{L T P D}=0.5$.

\begin{tabular}{|c|c|c|c|c|c|c|c|c|}
\hline \multirow[b]{2}{*}{$n$} & \multicolumn{2}{|c|}{$\lambda=0.10$} & \multicolumn{2}{|c|}{$\lambda=0.15$} & \multicolumn{2}{|c|}{$\lambda=0.20$} & \multicolumn{2}{|c|}{$\lambda=0.29$} \\
\hline & $\boldsymbol{k}$ & $c$ & $\boldsymbol{k}$ & $c$ & $\boldsymbol{k}$ & $c$ & $\boldsymbol{k}$ & $c$ \\
\hline \multicolumn{9}{|c|}{$\left(C_{A Q L_{2}}=1.6, C_{L T P D_{2}}=1.4, C_{A Q L_{1}}=1.0, C_{L T P D_{1}}=0.9\right)$} \\
\hline 2 & 39 & 0.5254 & 57 & 0.5221 & 77 & 0.5223 & 116 & 0.5222 \\
\hline 4 & 35 & 0.5275 & 55 & 0.5277 & 76 & 0.5273 & 116 & 0.5275 \\
\hline 5 & 35 & 0.5286 & 53 & 0.5286 & 77 & 0.5295 & 110 & 0.5287 \\
\hline 10 & 30 & 0.5297 & 46 & 0.5296 & 61 & 0.5289 & 95 & 0.5292 \\
\hline 15 & 27 & 0.5291 & 40 & 0.5278 & 53 & 0.5274 & 80 & 0.5277 \\
\hline 20 & 23 & 0.526 & 35 & 0.5256 & 47 & 0.5254 & 72 & 0.5258 \\
\hline 25 & 20 & 0.5233 & 31 & 0.5234 & 42 & 0.5243 & 66 & 0.5250 \\
\hline 30 & 18 & 0.5225 & 28 & 0.5217 & 39 & 0.5237 & 58 & 0.5226 \\
\hline \multicolumn{9}{|c|}{$\left(C_{A Q L_{2}}=1.7, C_{L T P D_{2}}=1.5, C_{A Q L_{1}}=1.1, C_{L T P D_{1}}=1.0\right)$} \\
\hline 2 & 33 & 0.5104 & 53 & 0.51 & 68 & 0.5104 & 106 & 0.5112 \\
\hline 4 & 33 & 0.5181 & 52 & 0.5193 & 68 & 0.5174 & 105 & 0.5170 \\
\hline 5 & 33 & 0.5184 & 50 & 0.5195 & 69 & 0.5197 & 104 & 0.5191 \\
\hline 10 & 34 & 0.5262 & 50 & 0.5236 & 68 & 0.5243 & 103 & 0.5243 \\
\hline 15 & 30 & 0.5264 & 49 & 0.528 & 63 & 0.5259 & 97 & 0.5261 \\
\hline 20 & 29 & 0.5272 & 44 & 0.5262 & 60 & 0.526 & 90 & 0.5263 \\
\hline 25 & 27 & 0.5267 & 43 & 0.5261 & 58 & 0.5272 & 86 & 0.5265 \\
\hline 30 & 26 & 0.5259 & 41 & 0.5261 & 55 & 0.5254 & 81 & 0.5257 \\
\hline
\end{tabular}

Table 4. The plan parameters for the proposed plan when $\Delta C_{A Q L}=0.6$ and $\triangle C_{L T P D}=0.5$.

\begin{tabular}{|c|c|c|c|c|c|c|}
\hline \multirow[b]{2}{*}{$n$} & \multicolumn{2}{|c|}{$\lambda=0.50$} & \multicolumn{2}{|c|}{$\lambda=0.75$} & \multicolumn{2}{|c|}{$\begin{array}{c}\text { Wang's test } \\
\text { statistic }\end{array}$} \\
\hline & $k$ & $c$ & $k$ & $c$ & $k$ & $c$ \\
\hline \multicolumn{7}{|c|}{$\left(C_{A Q L_{2}}=1.6, C_{L T P D_{2}}=1.4, C_{A Q L_{1}}=1.0, C_{L T P D_{1}}=0.9\right)$} \\
\hline 2 & 234 & 0.5223 & 408 & 0.5222 & 682 & 0.5222 \\
\hline 4 & 223 & 0.5274 & 399 & 0.5276 & 667 & 0.5276 \\
\hline 5 & 216 & 0.5285 & 396 & 0.5286 & 647 & 0.5284 \\
\hline 10 & 185 & 0.5289 & 337 & 0.5298 & 551 & 0.5290 \\
\hline 15 & 159 & 0.5281 & 286 & 0.5275 & 473 & 0.5276 \\
\hline 20 & 139 & 0.5256 & 249 & 0.5255 & 417 & 0.5258 \\
\hline 25 & 124 & 0.5238 & 226 & 0.5246 & 373 & 0.5243 \\
\hline 30 & 114 & 0.5220 & 203 & 0.5221 & 340 & 0.5221 \\
\hline \multicolumn{7}{|c|}{$\left(C_{A Q L_{2}}=1.7, C_{L T P D_{2}}=1.5, C_{A Q L_{1}}=1.1, C_{L T P D_{1}}=1.0\right)$} \\
\hline 2 & 51 & 0.5111 & 361 & 0.5102 & 605 & 0.5103 \\
\hline 4 & 50 & 0.5169 & 366 & 0.5170 & 608 & 0.5170 \\
\hline 5 & 50 & 0.5191 & 365 & 0.5189 & 608 & 0.5191 \\
\hline 10 & 49 & 0.5248 & 363 & 0.5246 & 597 & 0.5246 \\
\hline 15 & 48 & 0.5253 & 336 & 0.5258 & 572 & 0.5265 \\
\hline 20 & 45 & 0.5265 & 320 & 0.5264 & 533 & 0.5261 \\
\hline 25 & 41 & 0.5263 & 305 & 0.5264 & 503 & 0.5264 \\
\hline 30 & 40 & 0.5273 & 291 & 0.5259 & 482 & 0.5257 \\
\hline
\end{tabular}


Table 5. Leather industry data with two suppliers.

\begin{tabular}{|c|c|c|c|c|c|c|c|c|c|c|}
\hline \multirow{2}{*}{ Level } & \multirow{2}{*}{$\begin{array}{c}\boldsymbol{X}_{i} \\
\text { (Temp.) }\end{array}$} & \multirow{2}{*}{$L S L_{i}$} & \multirow{2}{*}{$U S L_{i}$} & \multirow{2}{*}{ Target $_{i}$} & \multicolumn{3}{|c|}{ Supplier 1} & \multicolumn{3}{|c|}{ Supplier 2} \\
\hline & & & & & Mean & S.D. & $\hat{S}_{p k_{i}}$ & Mean & S.D. & $\hat{S}_{p k_{i}}$ \\
\hline 1 & 25 & 0.00400 & 0.06600 & 0.03500 & 0.03498 & 0.01249 & 0.8274 & 0.03453 & 0.01020 & 1.0120 \\
\hline 2 & 32 & 0.00600 & 0.10600 & 0.05600 & 0.05570 & 0.02675 & 0.6230 & 0.05508 & 0.01134 & 1.4650 \\
\hline 3 & 39 & 0.00800 & 0.16600 & 0.08700 & 0.08657 & 0.03405 & 0.7734 & 0.08543 & 0.01120 & 2.3312 \\
\hline 4 & 46 & 0.01600 & 0.20000 & 0.11000 & 0.11002 & 0.01806 & 1.6881 & 0.10998 & 0.01645 & 1.8517 \\
\hline 5 & 53 & 0.02000 & 0.24000 & 0.13000 & 0.12808 & 0.01853 & 1.9687 & 0.12934 & 0.01598 & 2.2926 \\
\hline
\end{tabular}

as $\hat{D}_{t}^{E W M A}=0.4896541$. According to the proposed plan, since $\hat{D}_{t}^{E W M A}>c=0.4300$, it can be concluded that Supplier 2 has significantly outperformed Supplier 1. Given this, the leather product by Supplier 2 is accepted and a lot of leather products by Supplier 1 are rejected.

\section{Concluding remarks}

The main objective of this study was to propose a designing methodology for a sampling plan based on Exponentially Weighted Moving Average (EWMA) statistic to inspect products supplied by two suppliers. The tables for different profiles were taken into consideration for practical purposes. The performance of the proposed sampling plan was compared with that based on the Wang's test statistic in terms of the required sample size. A comparison of both sampling plans revealed that the proposed plan based on EWMA statistic required a small sample size when determining the lot of products by two suppliers. The application of the proposed plan was also illustrated through the industrial data. Application of the proposed plan in the industry for product acceptance made it possible for the product by two suppliers to be inspected at the same time. The proposed sampling plan with multiple suppliers can be considered as the future research.

\section{Acknowledgements}

The author would like to thank the Editor and the anonymous reviewers for their significant comments, which improved the manuscript. The study by ChiHyuck Jun was supported by the technology development program (S2635405) funded by the Ministry of SMEs.

\section{References}

1. Weber, C.A., Current, J.R., and Benton, W. "Vendor selection criteria and methods", European Journal of Operational Research, 50, pp. 2-18 (1991).

2. Olhager, J. and Selldin, E. "Supply chain management survey of Swedish manufacturing firms", International
Journal of Production Economics, 89, pp. 353-361 (2004).

3. Montgomery, D.C., Introduction to Statistical Quality Control, John Wiley \& Sons, New York (2007).

4. Wang, F.K. "The difference test statistic for two suppliers with linear profiles", Quality and Reliability Engineering International, 32, pp. 69-78 (2016).

5. Daniels, L., Edgar, B., Burdick, R.K., and Hubele, N.F. "Using confidence intervals to compare process capability indices", Quality Engineering, 17, pp. 2332 (2004).

6. Hubele, N.F., Berrado, A., and Gel, E.S. "A Wald test for comparing multiple capability indices", Journal of Quality Technology, 37, pp. 304-307 (2005).

7. Polansky, A.M. "Permutation methods for comparing process capabilities", Journal of Quality Technology, 38, pp. 254-266 (2006).

8. Lin, C.J. and Pearn, W. "Process selection for higher production yield based on capability index $S_{p k}$ ", Quality and Reliability Engineering International, 26, pp. 247-258 (2010).

9. Wu, C.-W., Liao, M.-Y., and Yang, T.-T. "Efficient methods for comparing two process yields-strategies on supplier selection", International Journal of Production Research, 51, pp. 1587-1602 (2013).

10. Lin, C.-J. and Pearn, W.L. "Group selection for production yield among $k$ manufacturing lines", Journal of Statistical Planning and Inference, 141, pp. 15101518 (2011).

11. Lin, C.J. and Kuo, H.H. "Multiple comparisons with the best for supplier selection", Quality and Reliability Engineering International, 30, pp. 1083-1092 (2014).

12. Woodall, W.H. "Current research on profile monitoring", Produção, 17, pp. 420-425 (2007).

13. Noorossana, R., Saghaei, A., and Amiri, A., Statistical Analysis of Profile Monitoring, John Wiley \& Sons (2012).

14. Hosseinifard, S.Z. and Abbasi, B. "Evaluation of process capability indices of linear profiles", International Journal of Quality \& Reliability Management, 29, pp. 162-176 (2012).

15. Hosseinifard, S.Z. and Abbasi, B. "Process capability analysis in non normal linear regression profiles", Communications in Statistics-Simulation and Computation, 41, pp. 1761-1784 (2012). 
16. Ebadi, M. and Amiri, A. "Evaluation of process capability in multivariate simple linear profiles", Scientia Iranica, 19, pp. 1960-1968 (2012).

17. Ebadi, M. and Shahriari, H. "A process capability index for simple linear profile", The International Journal of Advanced Manufacturing Technology, 64, pp. 857-865 (2013).

18. Wang, F.K. "A process yield for simple linear profiles", Quality Engineering, 26, pp. 311-318 (2014).

19. Wang, F.K. and Guo, Y.C. "Measuring process yield for nonlinear profiles", Quality and Reliability Engineering International, 30, pp. 1333-1339 (2014).

20. Wang, F.K. "Measuring the process yield for simple linear profiles with one-sided specification", Quality and Reliability Engineering International, 30, pp. 1145-1151 (2014).

21. Aslam, M., Azam, M., and Jun, C.-H. "Multiple dependent state sampling plan based on process capability index", Journal of Testing and Evaluation, 41, pp. 340-346 (2013).

22. Aslam, M., Azam, M., and Jun, C.-H. "A new lot inspection procedure based on exponentially weighted moving average", International Journal of Systems Science, 46, pp. 1329-1400 (2015).

23. Arif, O.H., Aslam, M., and Jun, C.-H. "Acceptance sampling plan for multiple manufacturing lines using EWMA process capability index", Journal of Advanced Mechanical Design, Systems, and Manufacturing, 11, pp. 1-11 (2017).

24. Aslam, M., Azam, M., and Jun, C.-H. "Acceptance sampling plans for multi-stage process based on timetruncated test for Weibull distribution", The International Journal of Advanced Manufacturing Technology, 79, pp. 1779-1785 (2015).

25. Aslam, M., Azam, M., and Jun, C.-H. "A new sampling plan under the exponential distribution", Communications in Statistics-Theory and Methods, 46, pp. 644-652 (2017).

26. Balamurali, S., Aslam, M., and Liaquat, A. "Determination of a new mixed variable lot-size multiple dependent state sampling plan based on the process capability index", Communications in Statistics-Theory and Methods, 47, pp. 615-627 (2018).

27. Butt, K., Aslam, M., Wang, F.K., Lee, H., and Jun, C.-H. "Evaluation of two process yields in acceptance sampling plans", Journal of Testing and Evaluation, 46, pp. 756-763 (2018).

28. Tamirat, Y. and Wang, F.K. "Sampling plan based on the exponentially weighted moving average yield index for autocorrelation within linear profiles", Quality and Reliability Engineering International, 32, pp. 17571768 (2016).

29. Wang, F.K., Tamirat, Y., Lo, S.C., and Aslam, M. "Dependent mixed and mixed repetitive sampling plans for linear profiles", Quality and Reliability Engineering International, 33, pp. 1669-1683 (2017).
30. Fallah Nezhad, M.S. and Hoseini Nasab, H. "A new Bayesian acceptance sampling plan considering inspection errors", Scientia Iranica, 19(6), pp. 1865-1869 (2012).

31. Fallahnezhad, M.S., Qazvini, E., and Abessi, M. "Designing an economical acceptance sampling plan in the presence of inspection errors based on maxima nomination sampling method", Scientia Iranica, 25(3), pp. 1701-1711 (2018).

32. Aslam, M., Niaki, S., Rasool, M., and Fallahnezhad, M.S. "Decision rule of repetitive acceptance sampling plans assuring percentile life", Scientia Iranica, 19(3), pp. 879-884 (2012).

33. Balamurali, S. "Determination of a new sampling system based on exponentially weighted moving average", Sequential Analysis, 37, pp. 158-173 (2018).

34. Aslam, M., Azam, M., and Jun, C.-H. "Improved acceptance sampling plan based on EWMA statistic", Sequential Analysis, 34, pp. 406-422 (2015).

35. Aslam, M., Azam, M., and Jun, C.-H. "Mixed sampling plan based on exponentially weighted moving average statistic", Communications in Statistics-Theory and Methods, 45, pp. 6709-6719 (2016).

36. Aslam, M., Azam, M., and Jun, C.-H. "Sampling plan using EWMA statistic of regression estimator", Iranian Journal of Science and Technology, Transactions A: Science, 42, pp. 115-127 (2018).

37. Azam, M., Arif, O.H., Azam, M., and Ejaz, W. "Repetitive acceptance sampling plan based on exponentially weighted moving average regression estimator", Journal of Computational and Theoretical Nanoscience, 13, pp. 4413-4426 (2016).

38. Khan, N., Aslam, M., Jun, C.-H., and Hussain, J. "Design of acceptance sampling plan using a modified EWMA statistic", Communications in StatisticsTheory and Methods, 47, pp. 2881-2891 (2018).

39. Tamirat, Y. and Mulatu, M.A. "Exponentially weighted moving average yield index for lot sentencing in first order autoregressive between linear profiles", Industrial Engineering and Management Systems, 17, pp. 796-804 (2018).

40. Tamirat, Y. and Wang, F.K. "Acceptance sampling plans based on EWMA yield index for the first autoregressive process", Journal of the Operational Research Society, 70(7), pp. 1179-1192 (2019). DOI: 10.1080/01605682.2018.1487819

41. Wang, F.K. "A single sampling plan based on exponentially weighted moving average model for linear profiles", Quality and Reliability Engineering International, 32, pp. 1795-1805 (2016).

42. Wang, F.K. and Tamirat, Y. "Acceptance sampling plan based on an exponentially weighted moving average statistic with the yield index for autocorrelation between polynomial profiles", Communications in Statistics-Theory and Methods, 47, pp. 4859-4871 (2018). 
43. Yen, C.-H., Aslam, M., and Jun, C.-H. "A lot inspection sampling plan based on EWMA yield index", The International Journal of Advanced Manufacturing Technology, 75, pp. 861-868 (2014).

44. Amiri, A., Zand, A., and Soudbakhsh, D. "Monitoring simple linear profiles in the leather industry (a case study)", Proceedings of the 2nd International Conference on Industrial Engineering and Operations Management, Kuala Lumpur, Malaysia, January (2011).

\section{Biographies}

Muhammad Aslam received his MSc in Statistics (2004) from GC University Lahore with Chief Minister of the Punjab merit scholarship, M. Phil in Statistics (2006) from GC University Lahore with the Governor of the Punjab merit scholarship, and Ph.D. in Statistics (2010) from National College of Business Administration \& Economics Lahore under the kind supervision of Dr. Munir Ahmad. He worked as a lecturer of Statistics in Edge College System International from 2003-2006. He also worked as a Research Assistant in the Department of Statistics, GC University Lahore from 2006 to 2008. Then, he joined the Forman Christian College University as a lecturer in August 2009. He worked as an Assistant Professor at the same University from June 2010 to April 2012. He worked in the same department as an Associate Professor from June 2012 to October 2014. He worked as an Associate Professor of Statistics in the Department of Statistics, Faculty of Science, King Abdulaziz University, Jeddah, Saudi Arabia from October 2014 to March 2017. He taught summer courses as Visiting Faculty of Statistics at Beijing Jiaotong University, China in 2016. Currently, he is working as a Full Professor of Statistics in the department of Statistics, King AbdulAziz University Jeddah, and Saudi Arabia. He has published more than 360 research papers in national and international well-reputable journals. His areas of interest include reliability, decision trees, industrial statistics, acceptance sampling, rank set sampling, and neutrosophic statistics, and applied Statistics.

Muhammad Azam holds his MSc degree in Statistics from Islamia University Bahawalpur in 1996 with distinction (Gold Medalist). He also received his MPhil from QAU, Islamabad in 2006 and PhD from University of Innsbruck, Austria in 2010. He has been involved in teaching for different institutes for the last 21 years. He started his career as the Lecturer in Statistics from Punjab Education Department and served there for 13 years. In 2010, he joined the Forman Christian College University Lahore as an Assistant Professor and served there for five years. In 2015, he joined as an Associate Professor and Chairman of the Department of Statistics and Computer Science, UVAS, Lahore. On January 04, 2018, Dr. Azam was selected as the Professor of Statistics and also as the Chairman of the Department till March 13, 2018. On March 14, 2018, he was assigned the responsibility as the Dean of Faculty of Life Sciences Business Management (FLSBM). He has published more than 80 research articles mostly published in impact factor international journals. He has attended number of national and international conferences/workshops. His research interests include survey sampling, statistical quality control, decision trees and ensemble classifiers. He has produced 25 MPhil students. Currently, four $\mathrm{PhD}$ and four MPhil research students are working under his supervision.

Chi-Hyuck Jun was born in Seoul, Korea in 1954. He received his BSc (1977) in Mineral and Petroleum Engineering from Seoul National University, his MSc (1979) in Industrial Engineering from KAIST, and his PhD (1986) in Operations Research from University of California, Berkeley. Since 1987, he has been with the Department of Industrial and Management Engineering, POSTECH. Currently, he is a Professor emeritus. His research interest includes reliability and quality analysis and data mining techniques. He is a member of IEEE, INFORMS, and ASQ. 